\title{
Further Support for a Palaearctic Origin of Leishmania
}

\author{
Sara F Kerr ${ }^{+}$, Robert Merkelz, Christy MacKinnon
}

Biology Department, University of the Incarnate Word, 3801 Broadway, San Antonio, Texas 78209, USA

The fossil record and systematics of murid rodents, reservoirs of zoonotic cutaneous leishmaniasis in the Palaearctic, Oriental, African, Nearctic and Neotropical, strongly support a Palaearctic origin of Leishmania. The fossil record and systematics of phlebotomine sand flies reinforce this idea. Interpretations of molecular data that place the origin of Leishmania in the Neotropical are inconsistent with the natural histories of reservoirs and vectors. The evolutionary pattern of New World rats (Sigmodontinae) indicates that they may be the most important reservoirs of zoonotic cutaneous leishmaniasis throughout their range.

Key words: Leishmania mexicana - Sigmodontinae - Muridae - Lutzomyia - coevolution - biogeography

While there is consensus on the taxonomic groupings (summarized in Kerr 2000) and antiquity (Noyes 1998, Kerr 2000) of the Leishmanial Endotrypanum clade, the geographic locality of origin and root are disputed. Noyes (1998) hypothesized a Neotropical origin with the root between the Endotrypanum/L. hertigi clade and the L. (Viannia)/L. (Leishmania) clade; Kerr (2000) hypothesized a Palaearctic origin with the root between the Old World and New World $L$. Leishmania. The strength of the Palaearctic hypothesis lies in the congruence of the systematics and fossil record of reservoirs and vectors of Leishmania with the molecular data (Kerr 2000). Congruence between molecular and morphological patterns is strong evidence that the historical pattern has been discovered (Hillis 1987).

The cosmopolitan role of murid rodents as reservoirs for cutaneous leishmaniasis in the Palaearctic, Oriental, African, Nearctic, and Neotropical zoological regions (Ashford 1996) is the strongest evidence that Leishmania originated in the Palaearctic. According to Ashford (1996), reservoirs include Gerbillinae (Rhombomys in Central Asia, Psammomys in West Asia and North Africa, Meriones in Pakistan and India), Murinae (Arvicanthis and Mastomys in sub-Saharan Africa), and Sigmodontinae (Neotoma in the USA and

This work received financial support from National Institutes of Health Grants GM55337 and GM50080, and a University of the Incarnate Word Faculty Development Grant.

+Corresponding author. Fax: +210-829-3153. E-mail: sfkerr@attglobal.net

Received 13 April 2000

Aceepted 15 May 2000
Ototylomys in Belize). Lainson and StrangwaysDixon (1964) reported an infection in Nyctomys, indicating that it may also be a reservoir. It seems reasonable to conclude that the pattern of origination, dispersal and diversification of Leishmania would be congruent with that of its reservoirs (Kerr 2000). For example, the evolution of Sigmodontinae progressed from the neotomines of North America (including Neotoma), to tylomyines (including Ototylomys) and nyctomines (including Nyctomys) of Central America. Nyctomines form a phenetic link between North American neotomines and South American groupings such as the thomasomyines and the oryzomyines (Eisenberg 1989), suggesting that these groups deserve closer investigation as possible reservoirs of L. mexicana in South America. Sigmodontinae are identifiable as early as the Miocene in North America; although most investigators date entry into South America at the Pliocene, there is some support for initial entry in the Miocene before the uplift of the Isthmus (Eisenberg 1989). Noyes et al. (1997) suggested that the presence of L. mexicana in the Dominican Republic indicated that Leishmania parasites can be carried across open water in hosts or vectors. If this was the case, then Leishmania may have also been introduced into South America during the Miocene, allowing a much longer time span for its diversification and dispelling one of the greatest difficulties with the hypothesis of a Palaearctic origin.

Noyes (1998) cited reclassification of the Lutzomyia vexator series into the new subtribe Sergentomyiina with Old World Sergentomyia (Galati 1995), which includes the vectors of Sauroleishmania, as support of a Neotropical origin of Leishmania. He incorrectly stated that a member of the vexator series was implicated as a vector of L. mexicana in Texas; the only known vector of 
Leishmania in the USA is Lu. anthophora (McHugh et al. 1993), which Galati places in the subtribe Lutzomyiina. Dujardin et al. (1999) state that the close relationship they found between Lutzomyia and Phlebotomus was predicted by Noyes (1998) hypothesis of a Neotropical origin of Leishmania. In fact, classifications by either Galati (1995) or Dujardin et al. (1999) support either a Neotropical or Palaearctic origin of Leishmania equally.

A difficulty with the idea that Endotrypanum is at the base of the Leishmania/Endotrypanum clade is the fact that published trees of this clade are inadequately rooted. For example, Croan et al. (1997) used Endotrypanum as an outgroup for a tree of the Leishmania/Sauroleishmania lineage and Noyes et al. (1997) used an unnamed trypanosomatid intermediate between Crithidial Leptomonas and Endotrypanum/Leishmania as an outgroup for the Leishmania/Endotrypanum lineage. In neither case was the outgroup clearly demonstrated to have evolved first, nor were plesiomorphic, synapomorphic or apomorphic character states made explicit. A well-rooted tree of the Leishmania/Endotrypanum clade that supports the Palaearctic origin of Leishmania can be constructed based on the presence or absence of the GP46/M-2 gene family, using Crithidia as an outgroup (Fig. 1). The gene family is present in $L$. mexicana, L. major, $L$. donovani, S. tarentolae and $C$. fasciculata and absent in L. (Viannia) (McMahon-Pratt et al. 1992), L. enrietti (Hanekamp \& Langer 1991) and Paraleishmania (Cupolillo et al. 2000). Another simplistic but congruent tree can be constructed based on reservoir hosts (Fig. 2), with Leishmania coevolving with the murid lineage, then expanding first to endemic hystricomorph rodents (including porcupines and echimyid rodents), and then sloths in South America.

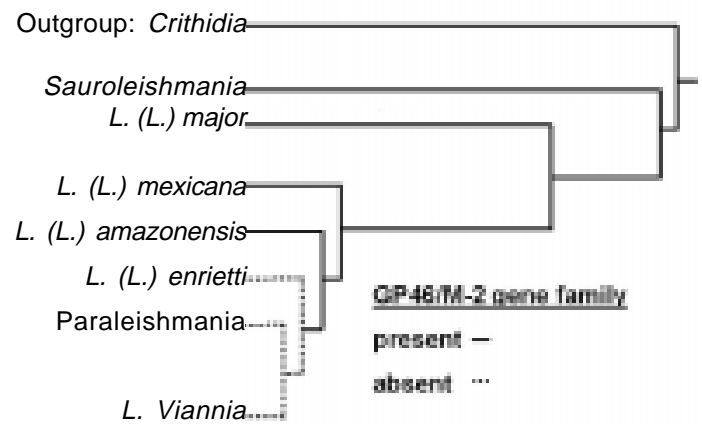

Fig. 1: phylogenetic tree of Leishmania based on the assumption that presence of the GP46/M-2 gene family is a primitive character.

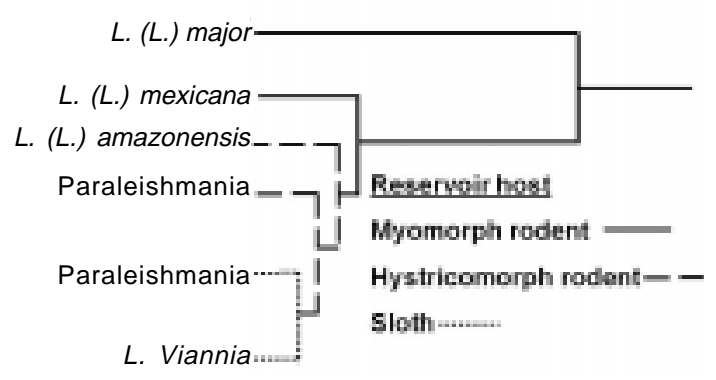

Fig. 2: phylogenetic tree of Leishmania based on reservoir hosts.

The concept that the locality where a taxa encompasses the greatest genetic diversity is the locality where a lineage originated permeates the molecular literature (Kerr 2000), but ignores the influence of isolation (on islands or mountain peaks) and climatic change on diversification (Vrba 1992, Cox \& Moore 2000). The observation by Noyes et al. (1997) of a distinctive strain of L. mexicana in the Dominican Republic is a classic example of diversification resulting from isolation which illustrates one mechanism that caused rapid diversification of Leishmania in South America and supports a Palaearctic origin of the genus. Empirical evidence that adaptive differentiation occurs when populations are subdivided on islands may be found in studies of Anolis lizards by Losos et al. (1997).

The evolutionary origin of Leishmania can be investigated further with molecular analyses of intraspecific DNA diversity. The great intraspecific diversity of L. mexicana reported by Cupolillo et al. (1998) may be the result of isolation of populations on islands and mountain peaks, or within various reservoir hosts. This hypothesis could be tested with isolates of L. mexicana, which is very widely dispersed geographically, from Arizona in the USA (Kerr et al. 1999), to the Andes in Ecuador (Hashiguchi et al. 1991). Ecological investigations of enzootic foci of Leishmania, in the style of Lainson and Strangways-Dixon (1964), but with the collaboration of molecular biologists, are of critical importance to clarify the evolution of the genus.

\section{ACKNOWLEDGEMENTS}

To CP McHugh, whose insights over the past decade motivated this paper, and to H Noyes for his courtesy and generosity with information.

\section{REFERENCES}

Ashford RW 1996. Leishmaniasis reservoirs and their significance in control. Clin Derm 14: 523-532.

Cox BC, Moore PD 2000. Biogeography. An Ecological and Evolutionary Approach, 6th ed., Blackwell Science Ltd, Oxford, x + 298 pp.

Croan DG, Morrison DA, Ellis JT 1997. Evolution of 
the genus Leishmania revealed by comparison of DNA and RNA polymerase gene sequences. $\mathrm{Mol}$ Biochem Parasit 89: 149-159.

Cupolillo E, Momen H, Grimaldi Jr G 1998. Genetic diversity in natural population of New World Leishmania. Mem Inst Oswaldo Cruz 93: 663-669.

Cupolillo E, Noyes H, Momen H, Grimaldi Jr G 2000. A revised classification for Leishmania and Endotrypanum. Parasitol Today 16: 142-144.

Dujardin JP, LePont F, Martinez E 1999. Quantitative phenetics and taxonomy of some phlebotomine taxa. Mem Inst Oswaldo Cruz 94: 735-741.

Eisenberg JF 1989. Mammals of the Neotropics. The Northern Neotropics. Volume 1. Panama, Colombia, Venezuela, Guyana, Suriname, French Guiana, The University of Chicago Press, Chicago and London, $\mathrm{x}$ + 449 pp.

Galati EAB 1995. Phylogenetic systematics of phlebotominae (Diptera, Psychodidae) with emphasis on American groups. Bol Dir Malariol y San Amb XXXV, (Supl. 1): 133-142.

Hanekamp T, Langer PJ 1991. Molecular karyotype and chromosomal localization of genes encoding two major surface glycoproteins, gp63 and gp46/M2, hsp70, and beta-tubulin in cloned strains of several Leishmania species. Mol Biochem Parasitol 48: 27-37.

Hashiguchi Y, Gomez EA, DeCoronel VV, Mimori T, Kawabata M, Furuya M, Nonaka S, Takaoka H, Alexander JB, Qhizhpe AM, Grimaldi Jr G, Kreutzer RD, Tesh RB 1991. Andean leishmaniasis in Ecuador caused by infection with Leishmania mexicana and L. major-like parasites. Am J Trop Med Hyg 44: 90165.

Hillis DM 1987. Molecular versus morphological approaches to systematics. Ann Rev Ecol Syst 18:
23-42.

Kerr SF 2000. Palaearctic origin of Leishmania. Mem Inst Oswaldo Cruz 95: 75-80.

Kerr SF, McHugh CP, Merkelz R 1999. Short report: a focus of Leishmania mexicana near Tucson, Arizona. Am J Trop Med Hyg 6: 378-379.

Lainson R, Strangways-Dixon J 1964. The epidemiology of dermal leishmaniasis in British Honduras: Part II. Reservoir-hosts of Leishmania mexicana among the forest rodents. Trans R Soc Trop Med Hyg 58: 136153.

Losos JB, Warheit KI, Schoener TW 1997. Adaptive differentiation following experimental island colonization in Anolis lizards. Nature 387: 70-74.

McHugh CP, Grogl M, Kreutzer RD 1993. Isolation of Leishmania mexicana (Kinetoplastida: Trypanosomatidae) from Lutzomyia anthophora (Diptera: Psychodidae) collected in Texas. J Med Entomol 30: 631-633.

McMahon-Pratt D, Traub-Cseko Y, Lohman KL, Rogers DD, Berverley SM 1992. Loss of the GP46/M-2 surface membrane glycoprotein gene family in the Leishmania braziliensis complex. Mol Biochem Parasit 50: 151-160.

Noyes H 1998. Implications of a Neotropical origin of the genus Leishmania. Mem Inst Oswaldo Cruz 93: 657-661.

Noyes HA, Arana BA, Chance ML, Maingon R 1997. The Leishmania hertigi (Kinetoplastida; Trypanosomatidae) complex and the lizard Leishmania: their classification and evidence for a Neotropical origin of the Leishmania-Endotrypanum clade. Euk Microbiol 44: 511-517.

Vrba ES 1992. Mammals as a key to evolutionary theory. J Mamm 73:1-28. 